\title{
WRITING-INTENSIVE COURSES ACROSS THE LAW CURRICULUM: DEVELOPING LAW STUDENTS' CRITICAL THINKING AND WRITING SKILLS
}

\author{
Theo Broodryk \\ $B A L L B$ \\ Lecturer, Faculty of Law, Stellenbosch University
}

\section{SUMMARY}

This article will explore the use of writina-intensive courses across the law curriculum, vested in the belief that writina, as an articulation of thinkina. enhances learning where it is meaningfully and intentionally embedded into a course structure. The article commences by pointing out that law students often regard the writing process and the critical thinking process as mutually exclusive and therefore fail to appreciate that writing is in fact the end-result of a process of argumentation or analysis. As a result of students' inability to engage effectively in a process of critical thinking, they tend to reach closure too quickly when presented with a critical-thinking problem. Consequently, students often fail to engage in a process of exploratory thinking, enabling them to suspend judgment and to enter into the spirit of opposing views. The article specifically focuses on the writing strategy recently implemented by the Faculty of Law, Stellenbosch University with the primary aim of establishing a coordinated approach to the development of research and writing skills within the LLB programme as an integral part of legal education within the Faculty. The Strategy is intended to enhance the writing and research skills of LLB students through a number of interrelated interventions implemented across the entire LLB programme. A principal aim is to inculcate both generic and specific writing skills in LLB graduates in a manner that is integrated into the curriculum. A key component of the Strategy, on which the article will focus, entails the identification and development of writing-intensive courses in terms of which writing and research assignments are integrated into substantive courses. Writing-intensive courses support the notion of "writing to learn" as opposed to "learning to write" and thus encourage critical thinking. They are assignment-centred rather than text- and lecture-centred; they are structured so as to enable exploratory thinking (and thus writing); they encourage students to become actively involved in their own learning processes; and they consist of assignments that require students to arrive at well-reasoned conclusions and solutions, testing them against relevant criteria and standards, justifying their ideas in writing or other appropriate modes. In these courses, students are instructed on writing skills alongside the substantive content of the particular course and given exercises to develop such skills with reference to the substantive content of the course. Each course is focused on specific writing skills and successive courses are focused on developing these skills. The article concludes by dealing with the practical difficulties and benefits associated with the development of writing-intensive courses, one of which is the fact that students not only develop generic writing skills, but they also develop specific writing skills within the academic discourse of our environment - they therefore do not only learn to write, but to write in law. 


\section{$1 \quad$ INTRODUCTION}

An effective legal writer is someone who is proficient at legal method ${ }^{1}$ and legal writing. Effective legal writing involves the ability to communicate clearly, precisely and completely. The written word is selected and controlled with meticulous care; irrelevant information is omitted and relevant information is included. An effective legal writer is able to conceal the critical thinking process culminating in the written communication - the writing process is made to look easy. An effective legal writer guides the reader to position the information from which perspectives or thoughts are to be viewed, making the relevant connections between individual pieces of relevant information and legal theories - in other words, to force the reader to think about the material in precisely the way the writer wants the reader to engage with it. ${ }^{2}$ It is essentially concerned with controlling the construction of sentences and paragraphs. ${ }^{3}$ An effective legal writer also takes his or her audience into account and in the professional, legal world the expectation is generally that he or she should be able to communicate clearly, unambiguously and in plain language. ${ }^{4}$

Law students need to be able to communicate effectively in writing. However, law students often view their primary function as the acquisition of information that is "right" or "correct" and to relay the information when they are required to do so in an assignment or examination. Absent from the process is the ability to think critically. This is because students generally view the writing process and the critical-thinking process as being mutually exclusive and they, therefore, fail to see that writing is in fact the end-result of a process of argumentation or analysis. ${ }^{5}$ As a result of students' inability to engage effectively in a process of critical thinking, they tend to reach closure too hastily when presented with a problem that requires critical thinking. According to Bean, it is imperative that students, when they are confronted with a problem that requires critical thinking, engage in a process of exploratory thinking - such an approach enables students to suspend judgment and to enter into the spirit of opposing views, which necessarily involves the evaluation of evidence, the questioning of assumptions, and so forth. ${ }^{6}$

Legal educators have generally adopted one of two approaches in relation to the conduct of legal education, or a combination of both. These approaches distinguish between, on the one hand, instruction that is limited to theory and doctrine and focuses on the sources and rules of law and, on

\footnotetext{
"Legal method" is the process in terms of which the law is applied to specific factual situations from which justifiable conclusions are drawn.

2 Dernbach, Singleton II, Wharton and Ruhtenberg A Practical Guide to Legal Writing And Legal Method (1996) xxi-xxii.

3 Gopen "The Golden Pen Award: IRAC, REA, Where Are We Now, And Where Should We Be Going In The Teaching Of Legal Writing" 201117 The Journal of the Legal Writing Institute 1 3-4.

4 Dernbach at al A Practical Guide to Legal Writing And Legal Method xxi-xxii.

5 Bean Engaging Ideas: The Professor's Guide to Integrating Writing, Critical Thinking, and Active Learning in The Classroom (2011) 23-24.

6 Bean Engaging Ideas: The Professor's Guide to Integrating Writing, Critical Thinking, and Active Learning in The Classroom 8.
} 
the other hand, instruction that emphasises the skills that prepare students to enter the legal profession. Writing-across-the-curriculum programmes attempt to achieve a balance between both of the aforementioned approaches and are effective in enabling the development of students to become effective legal writers.

It may be prudent to, at this point, distinguish between teaching students how to write in order to become effective legal writers and engaging in legal writing in order for students to learn about the law. "Learning to write" is premised on the assumption that content must be mastered before students can become effective legal writers. Conversely, "writing to learn" views writing as a key to learning itself - it is premised on the assumption that writing skills are essentially thinking skills and that, through writing, one develops an understanding of what one seeks to know. ${ }^{8}$ The latter approach is aimed at increasing and integrating skills-instruction with doctrinal information - "writing to learn" has become the standard model of writingacross-the-curriculum-efforts. The point of departure is that students learn best when they are taught to write about a subject matter they find relevant and that the act of writing is an effective tool to enable students to learn course material. ${ }^{9}$

In 2011, the Faculty of Law, Stellenbosch University (Faculty), implemented a writing-across-the-curriculum-strategy (Strategy) with the aim of establishing a coordinated approach to the development of research and writing skills within the undergraduate LLB programme as an integral part of legal education within the Faculty. A Faculty Task Team conceived the Strategy and it was approved by the Faculty Board in 2010. The University's Centre for Teaching and Learning (Centre) has been highly supportive of the Strategy and the Centre remains interested in the Strategy as a possible model for Stellenbosch University as a whole.

This article will explore the use of writing-intensive courses across the curriculum, vested in the belief that writing, an articulation of thinking, enhances learning where it is meaningfully and intentionally embedded into a course structure. It specifically focuses on the Strategy with its principal aim to inculcate both generic and specific writing skills in LLB graduates in a manner that is integrated into the curriculum. The Strategy consists of various components, a key component of which entails the identification and development of writing-intensive courses in terms of which writing and research assignments are integrated into substantive courses. The Faculty's

7 According to Thrower "Teaching Legal Writing Through Subject-Matter Specialties: A Reconception of Writing Across The Curriculum" 200713 Legal Writing $13-4$, a further approach to writing-across-the-curriculum is, rather than importing writing skills into a doctrinal course, to export doctrine into the legal writing classroom. In this regard, legal writing skills can be taught with a purposeful doctrinal focus where students learn the skills of writing and analysis while working through the nuances of a legal specialty to which they anticipate a long-term commitment.

8 Ibid; and Lashley and Wittstadt "Writing Across the Curriculum: An Integrated Curricular Approach to Developing Critical Thinking Through Writing" 199332 Journal of Nursing Education 422.

$9 \quad$ Kolb, Longest and Jensen "Assessing the Writing Process: Do Writing-Intensive First-Year Seminars Change How Students Write?" 201241 Teaching Sociology 20; and Weinberg "Overcoming Skepticism About 'Writing Across The Curriculum'” 1993 39(41) The Chronicle of Higher Education B2. 
writing-intensive courses reinforce its support of "writing to learn" as opposed to "learning to write" in encouraging the development of students' ability to actively engage in a process of critical thinking. The article concludes by dealing with the practical difficulties and benefits associated with the development of writing-intensive courses, one of which is the fact that students not only develop generic writing skills, but they also develop specific writing skills within the academic discourse of our environment they therefore do not only learn to write, but to write in law.

\section{WRITING-ACROSS-THE-CURRICULUM}

Writing-across-the-curriculum is an educational initiative that originated in Britain at the secondary school level in the 1960s and was adopted to undergraduate higher education in the United States in the 1970s. Stock states as follows in relation to the writing-across-the-curriculum-movement:

"From 1966-1971 educators led by James Britton and based at The University of London's Institute of Education studied the development of writing abilities of 11-18-year-old students (Britton, Burgess, Martin, Mcleod, \& Rosen, 1975). When preparing to publish, the researchers sought a means of convincing their professional colleagues to adopt the teaching practices their findings suggested. In an effort to capture the imagination of their fellow teachers and direct it to the institutional practices they wished to foster, Britton and the other members of the research team coined the slogan "writing across the curriculum.' This slogan was not meant to convince teachers of other subjects to behave the way some English teachers do when they 'correct' student papers for punctuation, grammar, and usage. Rather it was meant to remind all teachers at all levels of instruction that language - written and spoken - is the most readily accessible and powerful means of learning. A discussion of writing across the curriculum, then, is really an opportunity to explore the relationships between language and learning in the classrooms."

There is a growing and valuable body of scholarship embracing writingacross-the-law-school-curriculum as an educational initiative. Specifically, the focus has been on increasing the amount of transactional writing in law school; in other words, writing within professional genres that result in documents that are directed at various, specific audiences. Transactional writing generally occurs in doctrinal courses and is aimed at deepening students' subject-matter knowledge and analytic skill and assists in improving students' proficiency in professional writing conventions. A further approach under the writing-across-the-curriculum-movement, as has been mentioned above, is the importation of doctrinal teaching into legal writing classes to achieve the same purpose - to enhance students' learning to write in the discipline. ${ }^{11}$

Learning to write in the discipline should, according to the foremost body of scholarship, be the primary focus of writing-across-the-curriculumprogrammes as such an approach satisfies the four themes common to the three major theories of learning, namely behaviourism (the theory that

Stock "Writing Across the Curriculum" 198625 Theory into Practice 97.

11 McArdle "2008 AALS Annual Meeting Panel Discussion: 'Writing Across the Curriculum: Professional Communication and rhe Writing That Supports It"' 200915 Legal Writing 247 247-250. 
students can be taught to alter behaviour through exposure to various stimuli), cognitivism (the theory that students learn by interpreting new information and placing it within existing information structures stored in the brain) and constructivism (the theory that students create new knowledge, interpreting instruction in the context of their own experiences and their social relationships). According to Thrower, the four themes common to these three major learning theories are that:

- Instructors should begin instruction with basic material already within the students' grasp and thereafter proceed to grapple with more complex material;

- instructors should ideally instruct by making use of a variety of teaching methods;

- instructors should increase and deepen student-learning by having students apply newly developed skills and by giving feedback on the application thereof to, for example, a critical-thinking problem; and

- instructors should teach students how to become autonomous learners. ${ }^{12}$

According to Thower, these four themes support the merits of the learning-to-write-in-the-discipline-approach to writing-across-the-curriculum:

"Scholars posit that learning to write within a discipline is the approach to writing that a student must take in order to learn how to work as a particular professional. This is because learning to write in the discipline requires students to identify and master techniques and forms that are particular to that discipline, thereby making the students worthy of entering a restricted community made up only of people who know the particular forms something that is known as the discourse community. A law student needs to learn how to write in the discipline of lawyers as opposed to learning how to write in some other discipline - some other profession. Specifically, students need to learn the proper purposes of and audiences for legal word, the tones and formats of certain documents and the forms of reasoning particular to lawyers."

\section{WRITING-INTENSIVE COURSES}

In recognising that student-writing is a critical means to achieving important pedagogical and institutional goals, it is possible to incorporate studentwriting-into-law courses through teaching so-called "writing-intensive" courses. According to Bean, in developing a writing-intensive course, a course that supports "writing to learn" as opposed to "learning to write" and thus one that encourages critical thinking, the course should ideally:

- Be assignment-centred rather than text- and lecture-centred;

- be structured so as to allow time, space, tools and motivation for exploratory thinking and writing;

- encourage students to become actively involved in their own learning processes. In other words, students should be made to appreciate the

\footnotetext{
Thrower 200713 Legal Writing 21-22

3 Ibid.
} 
importance of wrestling with content rather than simply acquiring it and then conveying it when required to do so; and

- consist of assignments that are designed so as to require that students arrive at well-reasoned conclusions and solutions, testing them against relevant criteria and standards, justifying their ideas in writing or other appropriate modes. ${ }^{14}$

Assignment-design is therefore a critical element in the development of a writing-intensive course that is aimed at encouraging critical thinking. In this regard, the number of written assignments in a writing-intensive course is not as important as the design of the assignments themselves. ${ }^{15}$ According to Bean, an effective assignment is one that:

- Explains to students in clear and unambiguous terms what the purpose of the assignment is and what the instructor's expectations are in relation thereto; ${ }^{\prime \prime}$

- provides students with regular feedback and a continuous opportunity to consider and revise. In other words, simply editing the assignment will not suffice;

- encourages critical thinking;

- promotes self-reflection by the students which leads to a more meaningful and personal learning experience; ${ }^{17}$ and

- encourages students to write legibly and express themselves clearly. ${ }^{18}$

An effective assignment typically requires that students develop a "best solution" to an ill-structured problem; in other words, a problem that cannot be solved algorithmically to yield a single correct answer. It also requires that students justify the proposed solution with appropriate reasons and evidence. In designing an assignment, regard must be had to inter alia the students' level of expertise, their current degree of engagement with the subject matter and the nature of the question-asking in the instructor's discipline. ${ }^{19}$ Bean states that there are several things that the instructor must bear in mind when designing an assignment:

14 Bean Engaging Ideas: The Professor's Guide to Integrating Writing, Critical Thinking, and Active Learning in The Classroom 8.

15 Bean Engaging Ideas: The Professor's Guide to Integrating Writing, Critical Thinking, and Active Learning in The Classroom 1.

16 Grauerholz "Creating and Teaching Writing-Intensive Courses" 199927 Teaching Sociology 310311 , states that there is a real danger that in simply adding written assignments without careful consideration of how they are linked explicitly to specific course goals and objectives, one is wasting students' time and interfering with their learning as well as instructors wasting their own time and interfering with their own teaching.

17 Bean Engaging Ideas: The Professor's Guide to Integrating Writing, Critical Thinking, and Active Learning in The Classroom 2.

18 Neethling, Potgieter and Scott Workbook for the Law of Delict 2ed (1997) 6.

19 Bean Engaging Ideas: The Professor's Guide to Integrating Writing, Critical Thinking, and Active Learning in The Classroom 6; and Boye "How do I Create Meaningful and Effective Assignments?" Teaching, Learning, and Professional Development Center Texas Tech University http://www.tlpd.ttu.edu/teach/TLTC\%20Teaching\%20Resources/CreatingEffec tiveAssignments.asp (accessed 2012-12-11). 
- The instructor will need to articulate the purpose of the assignment - it should not be assumed that students will understand what the purpose of the assignment is even though it may seem obvious to the instructor. This will assist students in understanding how the assignment fits into the learning outcomes and why it is necessary for them to complete the assignment more thoughtfully.

- The instructor must use verbs that are precise in communicating to the students what they are required to do. ${ }^{20}$

- The instructor must define the audience. Students should, especially in a legal context, be made to understand that legal writing can take various forms and can be intended for various audiences, depending on the context within which the communication takes place. A heads of argument will, for example, have a different audience compared to informal correspondence addressed to a client or professional colleague.

- The instructor should not allow the logistics of the assignment, such as length, font, style etc., to take precedence over the content of the assignment. The execution of the assignment is, after all, only a part of the critical thinking process - it should not be seen to constitute the entire framework within which students' written work are assessed. ${ }^{21}$

- The instructor should clarify the evaluation criteria for the assignment. It is important for students to know how they will be assessed and that their ability to deal critically with the content will form a substantial part of the evaluation. ${ }^{22}$

As soon as problems have been formulated and assignment design has taken place, there are various ways in which the assignments can be integrated into a module. Writing need not necessarily be formal. Students can be required to do behind-the-scenes exploratory writing on a daily basis. This form of low-stakes writing is generally informal, personal, not fully revised or edited and a seedbed for generating ideas, whilst simultaneously recording the critical-thinking process. Exploratory writing can, in itself, have a drastic impact on the achievability by students of the identified course outcomes in so far as students are encouraged and empowered to engage critically with the substantive content of the discipline through a process of writing to learn. ${ }^{23}$

20 Such as "describe", "discuss", "analyse", "argue", etc.

21 This does not mean that no regard should be had to students' ability to communicate effectively in writing. Students should, with inter alia assistance of the Faculty's writing consultants, be able to master the stylistic and mechanical aspects of writing and to write organized, concise and persuasive prose.

22 Boye "How do I Create Meaningful and Effective Assignments?" Teaching, Learning, and Professional Development Center Texas Tech University http://www.tlpd.ttu.edu/teach/TLT C\%20Teaching\%20Resources/CreatingEffectiveAssignments.asp (accessed 2012-12-11).

23 Bean Engaging Ideas: The Professor's Guide to Integrating Writing, Critical Thinking, and Active Learning in The Classroom 6-8. 


\section{OVERVIEW OF THE STRATEGY}

The Strategy is a comprehensive one that extends across the undergraduate LLB programme and consists of a number of different and mutually complementary components. It has as its point of departure that the writing skills of students cannot be developed meaningfully by way of ad hoc, uncoordinated writing exercises in the course of LLB training. The Strategy is intended to enhance the writing and research skills of LLB students through a number of interrelated interventions implemented across the entire LLB programme. A principal aim is to inculcate both generic and specific writing skills in LLB graduates in a manner that is integrated into the curriculum. Apart from basic academic writing skills, regard is also to be had to forms of written communication specific to various branches of the legal profession and the commercial sphere. The Strategy also envisages that the focus on the development of writing skills be used as a vehicle for the improvement of legal research skills and the ability to disseminate the results of such activities. At the entrance level, the Strategy focuses on the development of writing skills as part of general academic literacy development in order to ensure that students have the necessary skills to be successful in their studies, while towards the exit-level the focus shifts to the development of graduate attributes relating to communication skills. To these ends, the Strategy comprises of:

- A first-year compulsory writing-skills development module (Writing Skills 171);

- the introduction of writing-intensive courses into the curriculum, in terms of which writing and research assignments are integrated into substantive courses;

- the assessment of the writing skills of students with reference to a standard writing framework of the Faculty;

- the appointment of Writing Consultants (Consultants) responsible for conducting one-on-one consultations with students as well as the conduct of lectures as part of Writing Skills 171. The Consultants advise students on improving inter alia the following aspects of their writing:

- Research

- Structure

- Argument

- Links between legal rules (principles), facts and applications

- Academic register

- Language

- Use of sources

- Referencing, and

- the continuous evaluation of results achieved with a view to the refinement and further development of the Strategy. 


\section{Writing skills}

During 2011, the administrative processes to have Writing Skills 171 approved were initiated and finalised, with the result that Writing Skills 171 was reflected in the Faculty's 2012 Yearbook as part of the curriculum as a compulsory module for all law students in their first year. Writing Skills 171 was therefore presented for the first time in 2012. It only makes sense that, as a first port of call, Writing Skills 171 should constitute the foundation in developing students' research and writing skills and that the identification and implementation of writing-intensive courses should be used as a platform to expand upon and further develop the skills of first-year undergraduate law students. The Strategy accordingly provides for a dedicated module dealing with writing and research skills as early as possible in the curriculum to provide the basis for the integrated development of more specialised writing skills at a later stage.

The first semester of Writing Skills 171 is presented by the Language Centre of the University and focuses on the development of general writing skills. The Language Centre is specifically tasked with providing to students an introduction to academic/legal language as well as teaching students how to develop an appropriate reading strategy. It also serves to identify students who might benefit from further training in an existing support programme during the second semester. The second semester of Writing Skills 171 is presented by the Faculty and focuses on more general skills relevant to legal research and legal writing and requires students to prepare different forms of written communication in a legal context. A coordinated approach is followed in terms of which students are provided with the theoretical information in respect of issues such as conducting research, reading, interpreting and analysing prescribed material, constructing an argument and effective legal writing, generally, but at the same time students are confronted with practical, contentious, significant and relevant exercises during which they are required to translate the theoretical information into practice. The aforementioned skills which Writing Skills 171 seeks to develop can be applied in the immediate academic context (for example, in assignments, tests and examinations) as well as in a professional, legal context, thus providing students with the necessary academically literacy skills to be successful in their studies, but also laying the foundation for the development of LLB-graduate attributes pertaining to professional communication skills.

\section{Writing framework}

An important overarching aspect of the Strategy is the compilation of a Faculty-specific writing framework that formulates the Faculty's writing practices and expectations. In this framework, the writing style used in the Faculty is detailed. This includes both the formal writing style and more content-related requirements. Both the teaching and assessment of writing skills takes place on the basis of this framework. Such a standard framework is important in order to serve as a teaching-development tool to improve teaching by and development of instructors at the Faculty; accomplish coordination and consistent implementation over the course of the 
undergraduate LLB programme (that is, so that different instructors do not state different requirements); aid effective learning by enabling progressive writing development; and force the Faculty to reflect on writing skills - why they are important and what the ideal end-product with regard to the writing skills of students should be. The compilation of an overarching framework thus enables the Faculty to identify the building blocks in the development of writing skills. The framework also describes the end-product regarding the writing skills of students. By compiling such a framework and providing it to the students as early as possible in the first year, the Faculty can communicate its expectations in this sphere to the students.

The framework is a key part of the Strategy since it enables instructors within particular course disciplines in the undergraduate programme to design learning opportunities that are aligned to the overarching Strategy. This is critical for the long-term sustainability of the Strategy as it captures the teaching development advanced under the Strategy in a single document that forms the basis of continued empowerment of individual law teachers; both those presently teaching law, but also future appointees.

\section{Co-ordinator: the strategy}

From a teaching and development perspective, the individual appointed as the Coordinator of the Strategy (Coordinator) inter alia assists in the development of teaching materials in consultation with instructors within individual courses aimed at developing discrete writing skills within those courses in a manner that is aligned to the overall Strategy. The Coordinator also assists instructors in developing teaching methodologies, suited to the particular substantive field, to integrate skills training within the substantive law being taught, including the development and presentation of training sessions and workshops within the Faculty to develop instructors' abilities to teach these skills.

\section{$44 \quad$ Writing consultants}

A further key strategic component of the Strategy is the Consultants. Seven Consultants were contracted by the Faculty in 2012 for an eight-month period, spanning from March to October 2012. In 2013 the Faculty appointed five Consultants for a nine-month period from February to October. The Consultants comprise a number of experienced post-graduate law students and other individuals with specialist language and writing skills, some of whom are qualified attorneys. They have an office in the Faculty, which office is manned by a different consultant every other day of the week (and a measure of rotation therefore takes place between them). The Consultants' office hours are $09 \mathrm{~h} 00$ to $17 \mathrm{~h} 00$, every day of the week during the term of appointment.

The Consultants are tasked with providing writing advice to the Faculty's undergraduate students. The successful implementation of the Strategy is dependent on the continuous involvement of the Consultants. Without the Consultants' continued involvement, it is unlikely that the skill levels of LLB students will improve as it has done since the implementation of the 
Strategy, or at all. This is because the Consultants are primarily responsible for teaching students (mostly through the conduct of one-on-one contact sessions), from a theoretical perspective, how to write properly (with regard to inter alia grammar, referencing, formulation and structuring of arguments, paragraphing, etcetera) whereafter it becomes the responsibility of inter alia the lecturing staff to translate the theoretical information into practice. It is furthermore clear that a close link between the Consultants and lecturing staff is a key aspect of the success of the Strategy.

\section{$45 \quad$ Monitoring}

The monitoring of the Strategy is evidence-based and draws on a sound knowlegde base. The research that takes place in this regard, is focused specifically on researching teaching and learning in an attempt to benefit the development of teaching and learning at the Faculty and the University. The Coordinator (and previously the Faculty's Committee for Teaching and Learning) and the Centre is tasked with the responsibility of monitoring the Strategy.

\section{$46 \quad$ Writing-intensive courses}

In each year of the undergraduate LLB programme, writing-intensive courses are identified in which specific attention is paid to the development of writing skills in addition to the substantive law under discussion. In each of these courses, very specific aims are set regarding writing skills and each year builds on the skills developed in the previous year(s). These aims are taught specifically - in other words, there are express sessions in the courses during which these writing skills are handled with the students these sessions can take place either in the form of main lectures, or in smaller groups such as tutorial sessions. However, such teaching is not separate from the substantive law under discussion in the module - it happens simultaneously. An important benefit of this approach is that the students not only develop generic writing skills, but develop specific writing skills within the academic discourse of our environment - they therefore do not only learn to write, but to write in law.

As from 2012, a number of courses across the curriculum were identified as writing-intensive courses. Although students are, as before, instructed on the substantive content of the particular course, particular attention in each of these courses is given to the development of designated writing and research skills by means of exercises designed to practise such skills using the substantive content of the course. Each such course has a particular aim regarding writing skills and successive courses will build on skills developed in preceding ones. The focus is on skills relevant to writing and research tasks typically required of legal practitioners (for example, in the giving of legal advice by way of memoranda, the drafting of documents and the drawing up of heads of argument and other papers).

In the identification of writing-intensive courses, close attention is paid to the alignment of specific writing skills and the content of the relevant courses. In this regard, for example, courses with procedural content could 
be well-suited to the development of more practical forms of writing, such as heads of argument. On the other hand, final-year electives can be used well for high-level academic writing skills.

The identification and development of writing-intensive courses occur through the conduct of regular one-on-one sessions between the Coordinator and the instructor of the specific writing-intensive course. This approach is aimed at enhancing the status of teaching and development at the Faculty in that instructors are guided through the transitional process ${ }^{24}$ whilst equipping them with the necessary skills to apply the contents of their discussions with the Coordinator to (other) courses for which they are responsible, and which courses have been identified as being writingintensive. This approach seeks to establish a sustainable methodology in terms of which the Faculty's instructors are able to develop their courses into writing-intensive courses to ensure that, ultimately, all courses at the Faculty embody an element that is focused on the development of students' research and writing skills in so far it is an essential premise of the Strategy. The benefits of the aforementioned approach are not limited to the development of instructors - a properly implemented and operational writingintensive module enables effective learning, that is, students write to learn, as opposed to learning to write, in a legal context. From a teaching and development perspective, the Coordinator therefore assists in the development of teaching materials in consultation with instructors within individual courses aimed at developing discrete writing skills within those courses in a manner aligned to the overall Strategy. The Coordinator assists instructors in developing teaching methodologies, suited to the particular substantive field, to integrate skills training within the substantive law being taught, including the development and presentation of training sessions and workshops within the Faculty to develop instructors' abilities to teach these skills.

\section{DIFFICULTIES AND PRACTICALITIES}

Although writing is a critical means to achieving important pedagogical and institutional goals, common problems associated with student writing, such as plagiarism or poorly written papers, can discourage the best-intentioned instructors from engaging in writing-across-the-curriculum-initiatives. Further contributing to instructors' reluctance to invest time in student-writing are institutional barriers such as large student enrolment, lack of teaching assistance, and increased pressure to devote time to research and publishing rather than teaching. ${ }^{25}$ The perception is also that written assignments will add an extra, intolerable, workload whilst classroom-time is already fully-scheduled. It is also the case that many instructors are not confident enough to teach writing skills and some simply do not enjoy writing themselves. ${ }^{26} \mathrm{~A}$ further common problem among instructors is that, by developing their courses into writing-intensive courses, they are not simply

24 Developing a specific course into a writing-intensive one.

25 Grauerholz 199927 Teaching Sociology 310.

26 Boice "Faculty Resistance to Writing-Intensive Courses" 199017 Teaching of Psychology 1314. 
being asked to add more writing to the courses - they are also being asked to change their style of teaching; the instructor would have to change from deductive to inductive teaching, from adopting a doctrinal approach to teaching to enabling students to do more figuring-out for themselves. ${ }^{27}$ Consequently, instructors may not adopt writing-to-learn tasks until the tasks seem obviously compatible with their own favoured instructional conditions. ${ }^{28}$

According to Grauerholz, adequate planning will diminish many of the problems associated with the development of writing-intensive courses. The reality is, however, that managing and teaching a writing-intensive course requires special effort and time on the part of instructors. Although there are no quick and easy strategies for eliminating the time and frustration inherent in managing and teaching writing-intensive courses, Grauerholz provides a few helpful suggestions in this regard:

- Revisions are essential and must go well beyond simply editing if writing is to contribute significantly to student learning. Requiring revisions is also one of the best ways to ensure effective legal writing and to avoid plagiarism.

- Adopt grading schemes that eliminate some of the time pressure on instructors, keeping in mind that not all writing-to-learn exercises need to be formal, evaluated or rewritten.

- Devote class-time to discussing what constitutes effective legal writing and how the written assignments seek to achieve this.

- Instructors need to be clear about their roles in helping students become effective legal writers.

- Enlist institutional help - seek out available resources or create supportstructures where they do not exist. ${ }^{29}$

Based on the Faculty's experience with and success in implementing the Strategy, the following practicalities should also be considered:

- The Strategy is dependent on outside funding but is progressively being incorporated into the Faculty's operational budget with strong support from the provost.

- The Coordinator and the Consultants are employed by the Faculty and thus reinforces the perception that the Strategy forms an important and integral part of legal education at the Faculty.

- The pedagogy underlining the Strategy is clear, deadlines are met and personality conflicts are minimal.

- The training of teaching assistants and Faculty members is carried out skilfully and regularly.

- Students learn during their first-year Writing Skills 171-course what is expected of them in their later writing-intensive courses. As a result,

27 Tchudi "The Hidden Agendas in Writing Across the Curriculum" 198675 The English Journal 22.

28 Kinneavy "Writing Across The Curriculum 1983 Profession 1317.

29 Grauerholz 199927 Teaching Sociology 317-319. 
many of the students enter the writing-intensive courses with a general understanding of how the additional workload will benefit them.

- Enough Faculty members have seen enough rewards from the extra work that a seemingly permanent enthusiastic core of teachers is now involved in the Strategy.

\section{CONCLUSION}

Writing is an essential tool for developing critical-thinking skills and it is most effective as a teaching tool when it is used to develop skills and to reinforce learning. The writing process necessitates committing to and engaging in a critical-thinking process and communicating the results of the process of argumentation and analysis in writing and in clear and unambiguous terms. ${ }^{31}$

The writing-across-the-curriculum movement has alerted the Faculty to the fact that it cannot simply assume that its students understand the writing practices, the varieties of discourse and discourse expectations students will be exposed to, both during their time at the Faculty and once they are in the workplace of the legal profession. ${ }^{32}$ As a result, through embracing a model of writing-across-the-curriculum, one needs to go beyond imitation and enable the development of students to become effective legal writers in several discourse communities that comprise the modern academic world. Because students are newcomers and because they learn through language, they must use the language they know to write about what they know and what they have experienced. ${ }^{33}$ In the words of Hanstedt:

"What writing across the curriculum recognizes then, is that students need more practice and more instruction in composition in order to become the writers we want them to be. Indeed, given that employers regularly cite writing (along with oral communication) as the top skills they look for in employees (Hart Research Associates 2010), and that most of our students were raised in the age of Twitter and Facebook, where an 'extended argument' equals all of 140 characters ${ }_{34}$ an emphasis on developing writing skills has become all the more important."

Weinberg 1993 39(41) The Chronicle of Higher Education B3.

31 Grauerholz 199927 Teaching Sociology 311-312.

32 Hanstedt "Reforming General Education: Three Reasons to Make Writing Across the Curriculum Part of the Conversation" 2012 98(4) Liberal Education 4849.

33 Stock 198625 Theory into Practice 99.

34 Hanstedt 2012 98(4) Liberal Education 48. 